\section{Commentary: Inspection of 3-dimensional rendered hearts will become the standard of care before complex congenital heart surgery}

\author{
Nicholas D. Andersen, MD, \\ Gregory M. Sturgeon, RDCS, MSE, \\ Piers C. A. Barker, MD, and \\ Joseph W. Turek, MD, PhD
}

In the current issue of JTCVS Techniques, Contreras and colleagues ${ }^{1}$ from Toronto report the case of a 7 -month-old child with complex transposition of the great arteries, ventricular septal defect (VSD), pulmonary stenosis, and single coronary artery who was evaluated for biventricular repair using echocardiography, magnetic resonance imaging (MRI), and a 3-dimensional (3D) printed heart. In the written report and the accompanying expert video presentation by Dr Barron, the authors demonstrate how the 3D printed model served as a useful adjunct for planning the surgical repair, which entailed a Yasui operation (Damus-KayeStansel/Rastelli) with VSD enlargement. The echocardiographic result and clinical course were similarly excellent, and the child was discharged home after 4 days.

Although a critic may argue that the 3D heart model was superfluous, and that the key information needed to plan the operation could have been retrieved entirely from the echocardiogram and MRI, it borders on the self-evident that careful examination of a physical 3D reconstruction of the heart before surgery improves decision making as well as intraoperative execution and error reduction. ${ }^{2-5}$ Simply put, if the goal of the preoperative imaging evaluation is

From the Duke Children's Pediatric and Congenital Heart Center, Duke University Medical Center, Durham, NC.

Disclosures: The authors reported no conflicts of interest.

The Journal policy requires editors and reviewers to disclose conflicts of interest and to decline handling or reviewing manuscripts for which they may have a conflict of interest. The editors and reviewers of this article have no conflicts of interest.

Received for publication Feb 11, 2021; revisions received Feb 11, 2021; accepted for publication Feb 22, 2021; available ahead of print Feb 27, 2021.

Address for reprints: Nicholas D. Andersen, MD, Division of Cardiovascular and Thoracic Surgery, Duke University Medical Center, 2301 Erwin Rd, DUMC 3474, Durham, NC 27710 (E-mail: Nicholas.Andersen@duke.edu).

JTCVS Techniques 2021;7:204-5

2666-2507

Copyright (c) 2021 The Authors. Published by Elsevier Inc. on behalf of The American Association for Thoracic Surgery. This is an open access article under the CC BY-NCND license (http://creativecommons.org/licenses/by-nc-nd/4.0/).

https://doi.org/10.1016/j.xjtc.2021.02.037
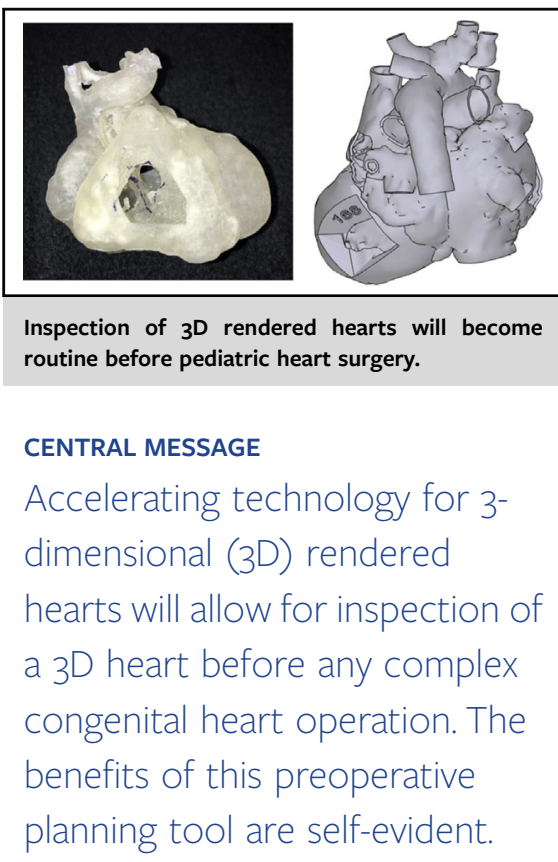

to create a noninvasive depiction of the physical structure of the heart, then the generation of a 3D model represents the ultimate fulfillment of this goal. Secondary benefits include use of the model as a teaching aid for surgeons, cardiologists, and imagers alike; surgical simulation; and creation of a shared understanding of the anatomic constraints of the operation between surgeons and cardiologists. $^{6}$

In real-world practice, however, creation of a 3D heart model is currently a cumbersome and time-consuming task that is poorly reimbursed (if at all). At our program, we are fortunate to have an imaging technician who specializes in creating $3 \mathrm{D}$ heart models. The time required for one model can include up to 10 hours for segmentation and preprocessing, 6 to 24 hours for printing, and 2 to 4 hours for postprocessing. Currently, none of this investment in specialized technician time, printing supplies, or printers is directly reimbursed, making the effort a cost sink for the program. Despite these barriers, however, we have found the models to be so incredibly helpful that we are now requesting 3D model generation before most complex operations, and particularly for understanding intraventricular baffle pathways (Figure 1, left), akin to the case report presentation. However, manipulation of a digital surface model in a 3D PDF file on a computer screen is often sufficient to understand the physical relationships of extracardiac structures, such as in patients with heterotaxy and complex systemic and pulmonary venous anomalies (Figure 1, right). Both of these segmentation-derived 

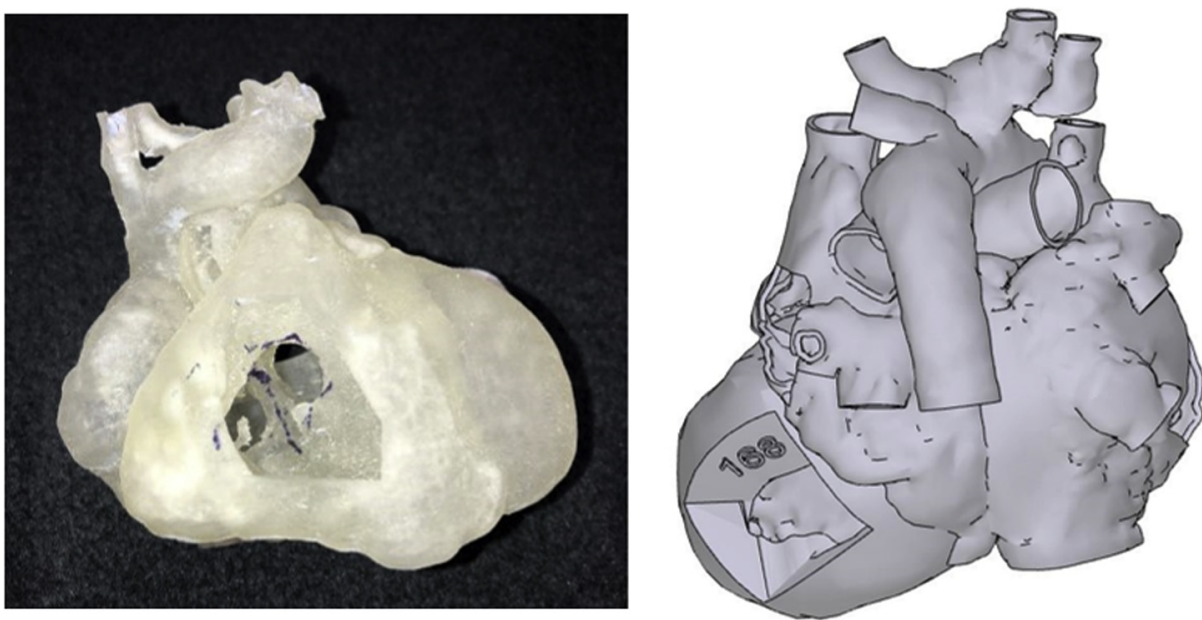

FIGURE 1. Examples of printed (left) and virtual (right) 3D rendered hearts.

techniques are superior to standard volumetric rendering techniques, which although capable of displaying the contrast-enhanced blood pool, fail to demonstrate intracardiac spatial relationships. Selective use of virtual 3D models in lieu of a printed heart allows for time and cost savings related to the printing process. In the last calendar year, our program performed approximately 350 index heart operations in children and produced 19 3D printed hearts and another 30 virtual 3D renderings before surgical or catheter-based intervention.

Although currently there are barriers to the generation of advanced 3D rendered hearts, we expect that these barriers will be quickly overcome, and that the technology will become a routine part of the preoperative assessment for most complex congenital heart operations. For the technology to accelerate, automation of the segmentation process with use of artificial intelligence, stereoscopic display, and "hollow" volume rendering could greatly reduce the time and labor investment required to create a model. Further advances in printing technology and physical materials will allow for the depiction of leaflet and chordal structures that currently are difficult to depict. Additional experience using 3D echo datasets as the backbone of the model will allow for model generation without the need for axial imaging in every case. Finally, for the technology to proliferate and truly become accepted as the standard of care before surgery, medical reimbursement will need to cover the costs associated with model generation. The important challenge will be to rigorously study the impact of 3D models on surgical outcomes, to prove that there is a benefit to patient care that justifies these costs. ${ }^{3,4}$

\section{References}

1. Contreras JR, Villemain O, Marini D, Dragulescu A, Yoo S-J, Barron DJ. Utility of a bespoke 3-dimensional printed model in complex transposition. J Thorac Cardiovasc Surg Tech. 2021;7:199-202

2. Yoo SJ, van Arsdell GS. 3D printing in surgical management of double outlet right ventricle. Front Pediatr. 2018;5:289.

3. Valverde I, Gomez-Ciriza G, Hussain T, Suarez-Mejias C, Velasco-Forte MN, Byrne N, et al. Three-dimensional printed models for surgical planning of complex congenital heart defects: an international multicentre study. Eur J Cardiothorac Surg. 2017:52:1139-48.

4. Zhao L, Zhou S, Fan T, Li B, Liang W, Dong H. Three-dimensional printing enhances preparation for repair of double outlet right ventricular surgery. $J$ Card Surg. 2018;33:24-7.

5. Bhatla P, Tretter JT, Ludomirsky A, Argilla M, Latson LA Jr, Chakravarti S, et al Utility and scope of rapid prototyping in patients with complex muscular ventricular septal defects or double-outlet right ventricle: does it alter management decisions? Pediatr Cardiol. 2017;38:103-14.

6. Yoo SJ, Thabit O, Kim EK, Ide H, Yim D, Dragulescu A, et al. 3D printing in medicine of congenital heart diseases. 3D Print Med. 2016;2:3. 